\title{
Suppression of mucosal Th17 memory responses by acellular pertussis vaccines enhances nasal Bordetella pertussis carriage
}

Violaine Dubois $\mathbb{i D}^{1 凶}$, Jonathan Chatagnon ${ }^{1}$, Anaïs Thiriard ${ }^{1}$, Hélène Bauderlique-Le Roy ${ }^{2}$, Anne-Sophie Debrie ${ }^{1}$, Loïc Coutte ${ }^{1}$ and Camille Locht $^{1}$

Pertussis has made a spectacular rebound in countries that have switched from whole-cell (wPV) to acellular pertussis vaccines (aPV). Here, we show that, unlike wPV, aPV, while protective against lung colonization by Bordetella pertussis (Bp), did not protect $\mathrm{BALB} / \mathrm{c}$ mice from nasal colonization, but instead substantially prolonged nasal carriage. aPV prevented the natural induction of nasal interleukin-17 (IL-17)-producing and interferon- $\gamma$ (IFN- $\gamma$ )-producing $\mathrm{CD}_{103}{ }^{+} \mathrm{CD}_{4} 4^{+} \mathrm{CD}_{69}{ }^{+} \mathrm{CD}^{+}$-resident memory $\mathrm{T}\left(\mathrm{T}_{\mathrm{RM}}\right.$ ) cells. IL-17-deficient, but not IFN- $\gamma$-deficient, mice failed to clear nasal Bp, indicating a key role of IL-17 ${ }^{+} \mathrm{T}_{\mathrm{RM}}$ cells in the control of nasal infection. These cells appeared essential for neutrophil recruitment, crucial for clearance of Bp tightly bound to the nasal epithelium. Transfer of IL-17 ${ }^{+} \mathrm{T}_{\mathrm{RM}}$ cells from Bp-infected mice to IL-17-deficient mice resulted in neutrophil recruitment and protection against nasal colonization. Thus, aPV may have augmented the Bp reservoir by inhibiting natural $T_{R M}$ cell induction and neutrophil recruitment, thereby contributing to the pertussis resurgence.

npj Vaccines (2021)6:6; https://doi.org/10.1038/s41541-020-00270-8

\section{INTRODUCTION}

Pertussis, also known as whooping cough, is a highly contagious respiratory disease, mainly caused by Bordetella pertussis (Bp). The most severe manifestations of pertussis occur in young children, but pertussis also affects adolescents, adults, and the elderly ${ }^{1}$. After the implementation of whole-cell pertussis vaccines (wPVs) combined with diphtheria- and tetanus-toxoid-based vaccines, referred to as DTP vaccines, in the 1950s and 1960s, the disease burden markedly lessened. However, concerns about the safety of wPV led to the replacement of DTP vaccines with diphtheria tetanus acellular pertussis vaccines (aPVs) in most industrialized countries in the 2000s. Less reactogenic than wPV, aPVs contain one to five purified $\mathrm{Bp}$ antigens and are highly effective in preventing pertussis disease ${ }^{2}$.

Despite high vaccination coverage, pertussis is now reemerging in several areas of the world ${ }^{3,4}$. Possible reasons that may contribute to this resurgence include improved diagnosis, the emergence of antigenic variants that escape vaccine-mediated immunity, suboptimal and fast waning immunity, especially after aPV vaccination ${ }^{5-7}$, and the inability of the current vaccines to prevent infection and transmission of $\mathrm{Bp}^{8,9}$.

Improving our understanding of pertussis pathogenesis and how vaccines may modulate $\mathrm{Bp}$ interactions with its host is needed to enhance whooping cough control. Although mice do not develop the characteristic cough associated with the disease, they share many features of human whooping $\operatorname{cough}^{10,11}$ and have been used in many studies to decipher immune mechanisms and various aspects of $\mathrm{Bp}$ infection ${ }^{12}$.

Bp clearance from the lungs of immunized mice has been shown to correlate with pertussis vaccine efficacy in children ${ }^{13-16}$. Similar to infection, immunization with wPV was associated with the induction of strong $\mathrm{T}$ helper type 1 (Th1)/Th17 immune responses, whereas aPV preferentially induces Th2 cells in mice ${ }^{13,14,16,17}$. Similar observations were reported in humans and in non-human primates $^{8,18}$. These Th subsets are mainly identified by signature cytokines such as interferon- $\gamma$ (IFN- - ) (Th1), interleukin-17 (IL-17) (Th17), and IL-4, IL-5, and IL-13 (Th2). Complementary roles for cellular and humoral immunity in protection have been identified in the mouse model, showing that both antibodies and $\mathrm{T}$ cell responses are important for protection. In prototypical Th1 C57BL/ 6 mice, lung infection by $\mathrm{Bp}$ is prevented by the accumulation of tissue-resident memory $T\left(T_{R M}\right)$ cells in the lungs ${ }^{19,20}$, and induction of $T_{R M}$ cells in the nose negatively correlates with nasal bacterial burden ${ }^{20}$. While vaccination with aPV strongly reduces the Bp load in the lungs, it does not protect against nasal carriage of $\mathrm{Bp}$ in the nasal cavity of mice ${ }^{21}$, consistent with its inability to do so in a nonhuman primate model ${ }^{8}$.

In this study, we took advantage of Th2-prone BALB/c mice to model the impact of aPV immunization on immune responses to $\mathrm{Bp}$ infection. This model was chosen as it reflects the situation in newborns, who are biased toward a Th2-type differentiation ${ }^{22}$. We report here that aPV immunization, while providing strong protection in the lungs, not only fails to protect against nasal colonization by $\mathrm{Bp}$ but also prevents natural clearing of $\mathrm{Bp}$ infection in the noses of BALB/c mice by suppressing Th17 $T_{R M}$ cell responses and ensuing neutrophil recruitment.

\section{RESULTS}

aPV immunization prolongs nasal carriage of Bp in Th2-prone mice To evaluate the relative protection conferred by WPV and aPV in the upper and lower respiratory tracts of mice, 6-week-old C57BL/ 6 and BALB/C mice were immunized twice subcutaneously with 1/ 10 human dose of Infanrix (aPV) or Shan5 (wPV) vaccine at a 4week interval or left unvaccinated as controls (Fig. 1a) and challenged intranasally 4 weeks after the second immunization with B1917GR, a gentamycin-resistant derivative of a clinical Bp strain representative of currently circulating strains ${ }^{23}$. The bacterial burden in the noses and lungs of the mice was determined by counting colony-forming units (CFUs) on the homogenized organs

${ }^{1}$ CNRS, Inserm, CHU Lille, Institut Pasteur de Lille, U1019-UMR9017-CIIL_Center for Infection and Immunity of Lille, Univ. Lille, 59000 Lille, France. ${ }^{2}$ CNRS, Inserm, CHU Lille, Institut Pasteur de Lille, US41_UMS 2014_PLBS, Univ. Lille, 59000 Lille, France. ${ }^{凶}$ email: violaine.dubois@ibl.cnrs.fr 

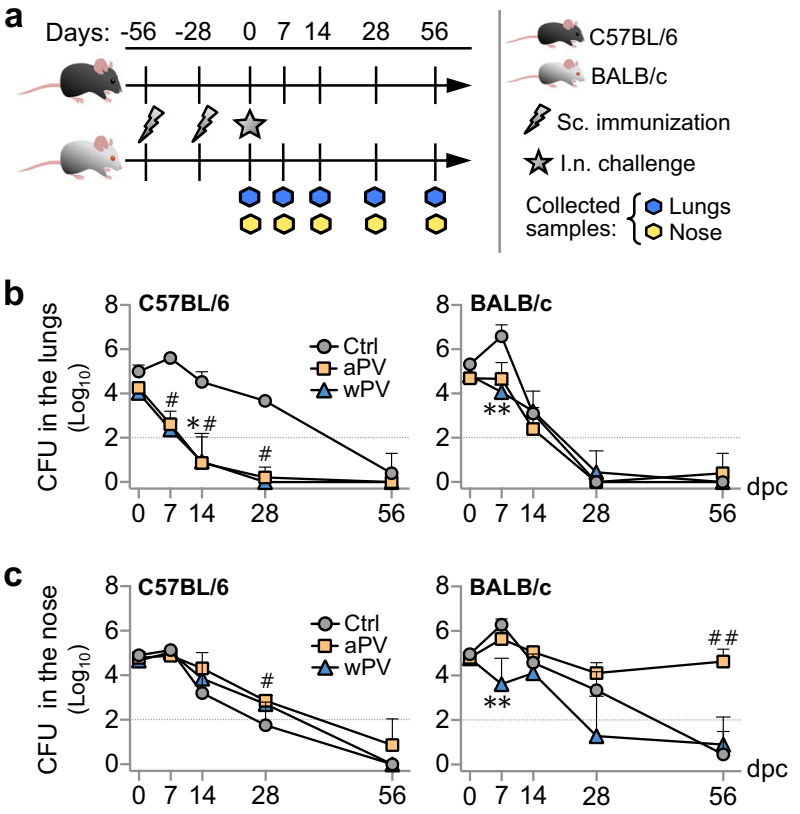

Fig. 1 aPV prolongs nasal carriage of $B p$ in $B A L B / c$ mice. a Schematic of vaccination and challenge protocol. Six-week-old C57BL/ 6 and BALB/C mice were immunized twice subcutaneously (s.c.) with $1 / 10$ human dose of Infanrix (aPV) or Shan5 (wPV) vaccine at a 4-week interval or left unvaccinated (Ctrl) and then nasally (i.n.) challenged with $10^{6} \mathrm{CFU}$ of B1917GR 4 weeks after the second immunization. Bacterial burden in the noses and lungs was determined by CFU counting at indicated time points post challenge on homogenized organs. b CFU counts on lung homogenates at indicated time points. c CFU counts on nose homogenates at indicated time points. Results shown are geometric means \pm SD. $n=$ 4-5. Kruskal-Wallis tests were performed to compare aPV- $(\#)$ and wPV- $\left.{ }^{*}\right)$ immunized mice to controls. Only significant differences are

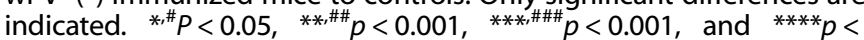
0.0001 . Dashed lines in CFU counts correspond to the detection limit.

at different times post challenge (p.c.) (3 hours p.c. (h.p.c.) (D0) and 7, 14, 28, 56 days p.c. (d.p.c.)) (Fig. 1a).

Both aPV and wPV protected equally well against lung colonization after infection with a high-dose challenge $\left(10^{6} \mathrm{CFU}\right)$ (Fig. 1b). Protection was also evident when the mice were infected with a lower dose $\left(10^{5} \mathrm{CFU}\right)$ (Supplementary Fig. 1a). However, neither vaccine protected against nasal infection of C57BL/6 mice (Fig. 1c, left panel), even when the mice were challenged with a moderate dose of Bp (Supplementary Fig. 1b, left panel). In BALB/c mice, immunization with wPV led to a slight, but significant reduction of nasal colonization at the early time points after infection, whereas aPV provided no protection at all (Fig. 1c, right panel and Supplementary Fig. 1b, right panel). Instead, vaccination with aPV resulted in significantly prolonged nasal carriage. The amounts of CFU in the nasal tissues were as high at 56 d.p.c. as they were in the beginning of the infection, with no trend of a decrease in bacterial load (Fig. 1c, right panel and Supplementary Fig. 1b, right panel).

Both BALB/C and C57BL/6 mice develop resident memory Th17 cells in the nose after Bp infection

IL-17-producing CD4 ${ }^{+} \mathrm{T}_{\mathrm{RM}}$ cells, expressing CD69, CD44, and/or CD103, were recently shown to correlate with protection against nasal colonization by $\mathrm{Bp}$ in $\mathrm{C} 57 \mathrm{BL} / 6 \mathrm{mice}^{20,24}$. We, therefore, investigated whether the Th2-prone $B A L B / c$ mice might be less efficient than $\mathrm{C} 57 \mathrm{BL} / 6$ mice in inducing these cells in the nasal tissues upon $\mathrm{Bp}$ infection. To identify $\mathrm{T}_{\mathrm{RM}}$ cells in the nasal tissues, mice were injected intravenously with an anti-CD45-PE antibody
(CD45iv), enabling us to distinguish infiltrated resident cells from circulating immune cells. Following the intranasal challenge, up to $\sim 30 \%$ of immune cells in the noses of BALB/C mice were lymphocytes expressing CD3 (Fig. 2a). Among the $\mathrm{CD}^{+}{ }^{+} \mathrm{T}$ cells, the proportion of $\mathrm{CD} 69^{+} \mathrm{CD} 4^{+} \mathrm{T}$ cells doubled 14 d.p.c. (Fig. 2a). These $\mathrm{CD} 9^{+} \mathrm{CD}^{+} \mathrm{T}$ cells up-regulated CD44 and CD103 expression over time after infection (Fig. 2a), indicating that $\mathrm{BALB} / \mathrm{c}$ mice were able to induce $\mathrm{T}_{\mathrm{RM}}$ cells in the nasal tissue after $\mathrm{Bp}$ infection. However, compared to C57BL/6 mice, expression of these $T_{R M}$ markers was somewhat delayed in BALB/c mice (Fig. $2 b)$. Nonetheless, at 14 d.p.c. C57BL/6 and BALB/c mice shared a similar expression pattern of both markers (Fig. 2b).

Measurement of IL-17- and/or IFN- $\gamma$-producing cells after stimulation with phorbol myristate acetate (PMA) and ionomycin in the presence of brefeldin $A$ showed that similar to $T_{R M}$ cells from C57BL/6 mice, $T_{R M}$ cells from BALB/c mice were activated quickly after challenge and expressed mainly IL-17 (Fig. 2c). However, only $14 \%$ of $T_{R M}$ cells from BALB/c mice versus $32 \%$ of $T_{R M}$ cells from C57BL/ 6 mice expressed IFN- $\gamma$ or both IL-17 and IFN- $\gamma 14$ d.p.c. (Fig. 2c). Thus, BALB/c mice are not intrinsically unable to induce nasal IL17-producing $\mathrm{CD}^{+} \mathrm{T}_{\mathrm{RM}}$ cells upon infection with $\mathrm{Bp}$.

aPV immunization impairs the induction of nasal Th1 and Th17 $\mathrm{T}_{\mathrm{RM}}$ cells in BALB/c mice upon Bp infection

As Bp infection leads to the induction of Th1 and Th17 $T_{R M}$ cells in the nasal tissues of $B A L B / c$ mice, we examined the effect of aPV or wPV immunization on Bp infection-induced $T_{R M}$ cells in the noses of these mice. Whereas upon Bp infection an increase in both $\mathrm{CD}_{103}{ }^{+} \mathrm{CD}_{4} 4^{+}$and $\mathrm{CD}_{103}{ }^{-} \mathrm{CD} 44^{+} \mathrm{T}_{\mathrm{RM}}$ cells was detectable among $\mathrm{CD}^{+} 9^{+} \mathrm{CD}^{+} \mathrm{T}$ cells in the nasal tissues of BALB/C mice from 7 d.p.c. on and peaking at 14 d.p.c., prior aPV vaccination completely abolished the induction of these cells (Fig. 3a, upper panels). Representative examples of $\mathrm{CD}_{103}{ }^{+} \mathrm{CD}_{4} 4^{+} \mathrm{T}$ cell enrichment among $\mathrm{CD}_{6} 9^{+} \mathrm{CD} 4^{+}$-resident $\mathrm{T}$ cells between 7 and 28 d.p.c. are shown in Fig. 3a (lower panels). In contrast, immunization with wPV did not inhibit the induction of $\mathrm{CD}^{+}$ $T_{R M}$ cells upon $B p$ infection, but instead resulted in earlier induction of the $\mathrm{CD}_{103^{+}} \mathrm{CD}_{4} 4^{+} \mathrm{T}_{\mathrm{RM}}$ cells that were significantly enriched 7 d.p.c. compared to non-vaccinated mice (Fig. 3a).

In addition, the $\mathrm{CD}_{103^{+}} \mathrm{CD}^{+} \mathrm{T}_{\mathrm{RM}}$ cells from aPV-immunized mice were poorly activated, as $<20 \%$ of $\mathrm{CD}_{103}{ }^{+} \mathrm{T}_{\mathrm{RM}}$ cells from aPV-immunized mice expressed IL-17 or IFN- $\gamma$ upon stimulation with PMA and ionomycin 7 or 28 d.p.c., whereas most of $(>50 \%)$ the stimulated $\mathrm{CD}_{103^{+}} \mathrm{CD}^{+} \mathrm{T}_{\mathrm{RM}}$ cells from control and wPVimmunized mice produced IL-17 and/or IFN- $\gamma 28$ d.p.c. (Fig. 3b). IL$17^{+} \mathrm{IFN}-\gamma^{+}$cells were also enriched in the $\mathrm{CD}_{103^{+}} \mathrm{CD}^{+} \mathrm{T}_{\mathrm{RM}}$ cell subset of control and wPV-immunized mice. No IL- $17^{+}$IFN- $\gamma^{+}$cells were detected in aPV-immunized mice. Absolute counts of IL-17 ${ }^{+}$ $\mathrm{T}_{\mathrm{RM}}$ and IFN- $\gamma^{+} \mathrm{T}_{\mathrm{RM}}$ cells show that IL-17 ${ }^{+} \mathrm{T}_{\mathrm{RM}}$ cells predominated in wPV-immunized mice (Fig. 3C, d). IL- $17^{+} \mathrm{CD} 103^{+} \mathrm{T}_{\mathrm{RM}}$ cells were significantly enriched in WPV-immunized mice compared to control mice 7 d.p.c., while at later time points after infection, the numbers of $\mathrm{IL}-17^{+} \mathrm{CD} 103^{+} \mathrm{T}_{\mathrm{RM}}$ cells tended to be higher in control mice than in wPV-immunized mice (Fig. 3c). A similar observation was made for the IFN- $\gamma$-producing $\mathrm{CD}_{103}{ }^{+} \mathrm{CD}^{+}{ }^{+} \mathrm{T}_{\mathrm{RM}}$ cells (Fig. 3d). Thus, early protection conferred by wPV against nasal colonization of $\mathrm{BALB} / \mathrm{C}$ mice was associated with a rapid expansion of $\mathrm{IL}-17^{+} \mathrm{CD} 103^{+} \mathrm{CD} 4^{+} \mathrm{T}_{\mathrm{RM}}$ and to a lesser extend IFN$\mathrm{Y}^{+} \mathrm{CD}_{103^{+}} \mathrm{CD}^{+} \mathrm{T}_{\mathrm{RM}}$ cells. In contrast to $\mathrm{WPV}$, aPV immunization totally inhibited the induction of these cells in the nasal tissues of Bp-infected BALB/c mice. A similar trend was also observed for IL-

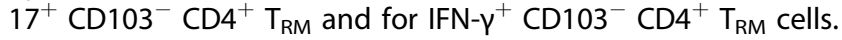

To examine whether the difference between the aPV and wPV effect on the inhibition of $T_{R M}$ cell induction in the nose of $B A L B / C$ mice might be related to differences in serum antibody responses to the two vaccines, we measured serum IgG titers to whole $B$. pertussis cell extracts in aPV- and in wPV-immunized mice before and after 
a

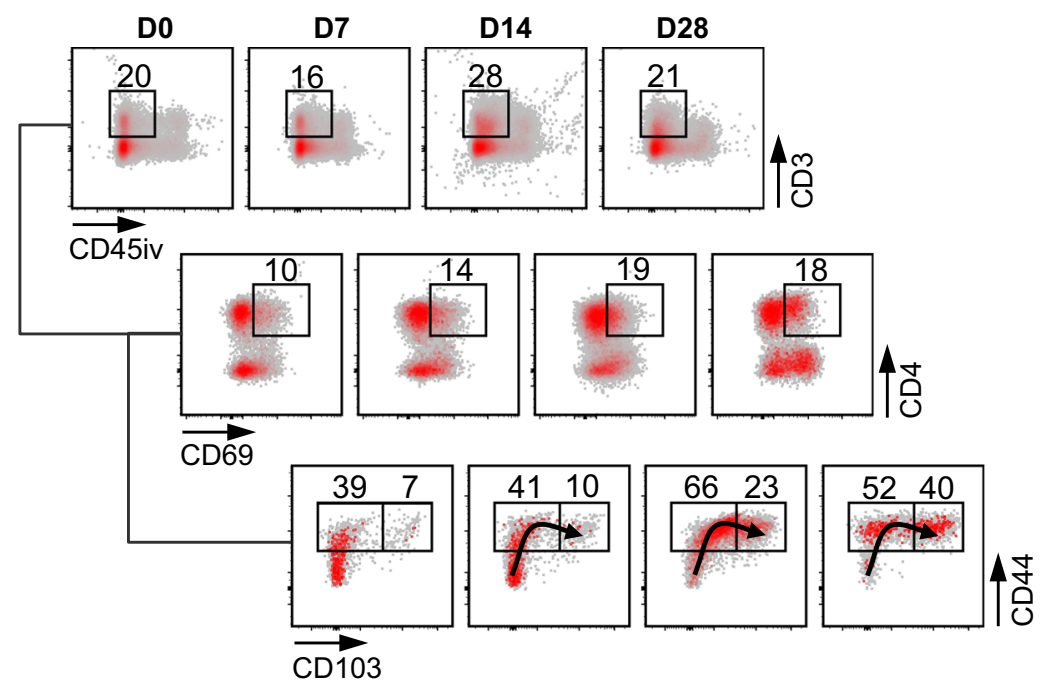

b

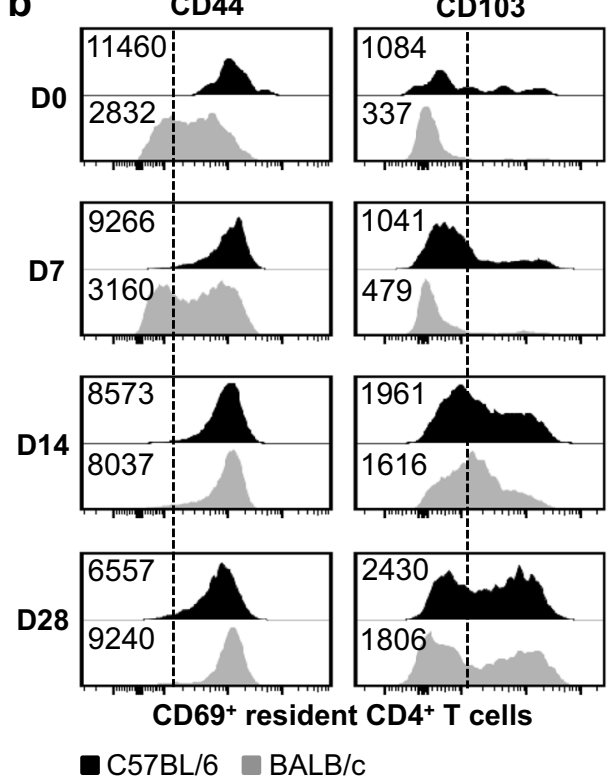

C
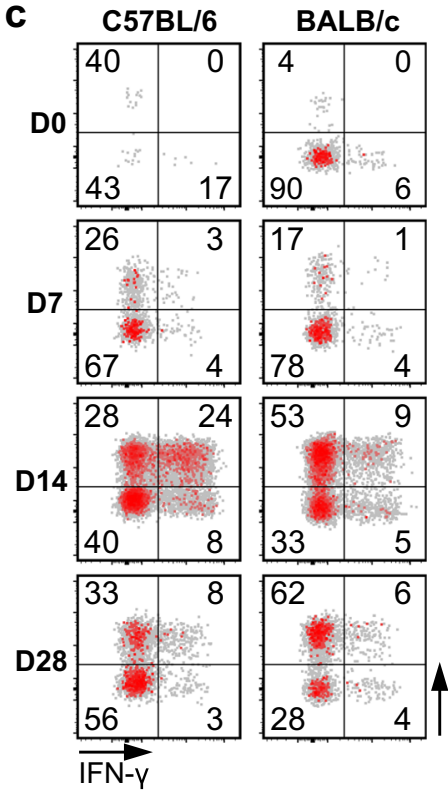

Fig. 2 Bp-infected BALB/c mice develop Th17 $\mathrm{T}_{\mathrm{RM}}$ cells in the nose. Six-week-old $\mathrm{C} 57 \mathrm{BL} / 6$ mice and $\mathrm{BALB} / \mathrm{c}$ mice were infected with $10^{6} \mathrm{CFU}$ of B1917GR. Nasal immune cells were collected at indicated time points post challenge (D0-D28). Ten minutes before euthanasia, mice were intravenously injected with anti-CD45-PE antibody enabling us to discriminate $T_{R M}$ cells from circulating cells. $T_{R M}$ cells express CD44, CD69, and/or CD103. Cell activation was assessed by nonspecific ex vivo stimulation and intracellular staining of IL-17 and IFN- $\gamma$. Cells were fixed and permeabilized to perform intracellular staining of IL-17 and IFN- $\gamma$. Numbers indicate percentages of events in each square. a Representative graph showing the accumulation of $\mathrm{CD}_{103^{+}} \mathrm{CD}_{4} 4^{+} \mathrm{T}_{\mathrm{RM}}$ cells in the nose of BALB/C mice at indicated time points after $\mathrm{Bp}$ challenge. b Representative graph comparing the pattern of expression of CD44 (left panels) and CD103 (right panels) in the nose of $\mathrm{C} 57 \mathrm{BL} / 6$ (black) and BALB/c mice (gray) at indicated time points after Bp challenge. Numbers indicate mean fluorescence intensities and dotted lines indicate the cut-off between positive and negative cells. c Representative graph showing the proportion of IL-17- and/or IFN- $\gamma$ producing $\mathrm{CD}^{+} \mathrm{T}_{\mathrm{RM}}$ cells in the nose of $\mathrm{C} 57 \mathrm{BL} / 6$ (left panels) and BALB/c mice (right panels) at indicated time points after Bp challenge. Numbers indicate percentages of events in each square.

B. pertussis challenge. Both before and after the challenge, wPV and aPV induced high levels of anti- $B$. pertussis serum antibodies (Supplementary Fig. 2). These titers were slightly, but significantly higher in wPV-immunized than in aPV-immunized mice, making it unlikely that the difference in nasal $T_{R M}$ cell induction was due to a blunting effect by aPV-induced serum antibodies.

IL-17 is essential for the control of nasal but not of lung infection by Bp

As aPV immunization appeared to prevent natural clearance of nasal Bp colonization and to inhibit the induction of IL-17- and/or
IFN- $\gamma$-producing $\mathrm{CD}^{+}{ }^{+} \mathrm{T}_{\mathrm{RM}}$ in the noses of Bp-infected BALB/C mice, we investigated the relative role of IL-17 and IFN- $\gamma$ in controlling nasal carriage of $\mathrm{Bp}$. IL-17 knockout (KO) mice and IFNY KO mice were infected nasally with $\mathrm{Bp}$, and lung and nasal colonization was followed over time. Whereas both KO mice cleared the lung infection as quickly as the control mice, regardless of the initial bacterial burden (Fig. 4a, left panel and Supplementary Fig. 3a, left panel), IL-17-deficient mice were unable to control nasal infection by $\mathrm{Bp}$ and carried the infection for at least 56 d.p.c. without a trend of decrease in bacterial load (Fig. 4a, right panel and Supplementary Fig. 3a, right panel). 
a
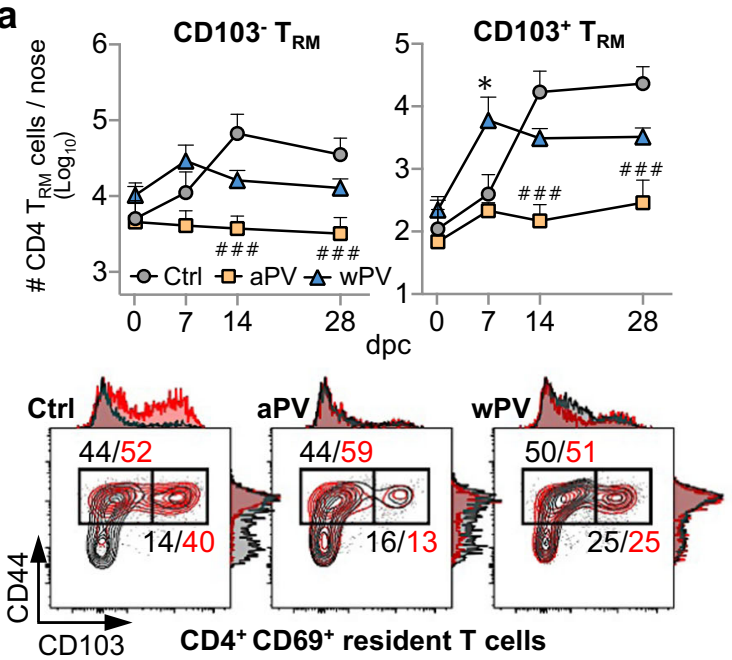

$\square 7 \mathrm{dpc} \quad \square 28 \mathrm{dpc}$

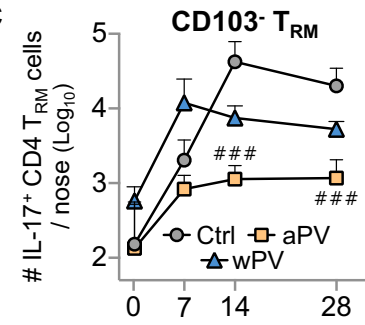

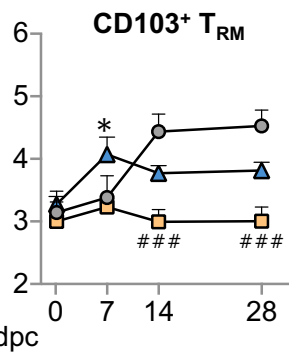

b

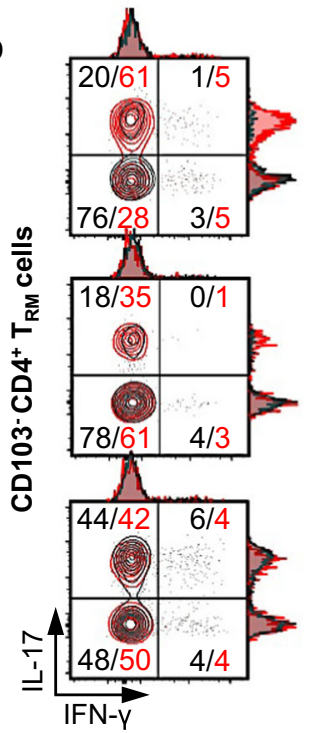

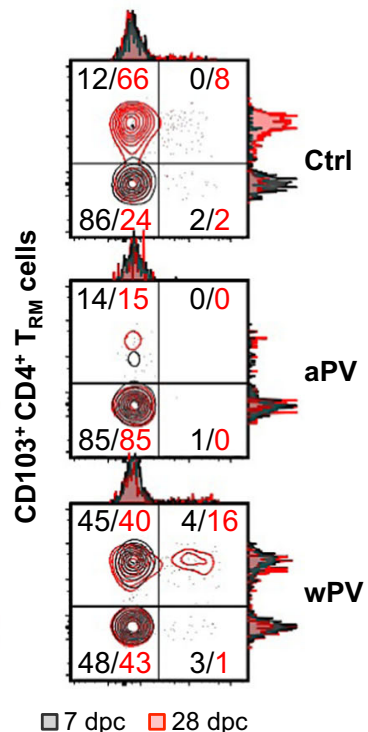

$\square 7 \mathrm{dpc} \quad \square 28 \mathrm{dpc}$

d

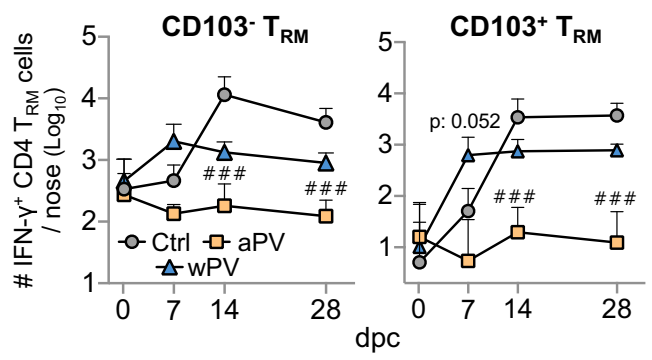

Fig. 3 aPV immunization impairs TRM cell induction in the noses of BALB/c mice. BALB/c mice were immunized twice with aPV or wPV or left unvaccinated (Ctrl) prior to challenge with $10^{6} \mathrm{CFU}$ of B1917GR and the induction of CD4 ${ }^{+} \mathrm{T}_{\mathrm{RM}}$ cells in the noses of mice was measured at the indicated time points. a Absolute numbers of nasal $\mathrm{CD}_{103^{-}}$(upper left panel) and $\mathrm{CD}_{103^{+}}$(upper right panel) $\mathrm{CD} 4^{+} \mathrm{T}_{\mathrm{RM}}$ cells and representative graph illustrating differential enrichment of $\mathrm{CD} 44^{+} \mathrm{CD} 103^{+}$among the $\mathrm{CD} 69^{+} \mathrm{CD} 4^{+}$resident T cells 7 (in black) and 28 d.p.c. (in red) in the nose of control and vaccinated BALB/c mice (lower panels). Numbers indicate percentages of events in each square. b Representative graphs showing the increase in IL-17- and/or IFN- $\gamma$-producing nasal CD103- (left panels) and CD103 ${ }^{+}$(right panels) CD4 ${ }^{+}$ $\mathrm{T}_{\mathrm{RM}}$ cells between 7 (in black) and 28 d.p.c. (in red). Numbers indicate percentages of events in each square. c Absolute numbers of IL-17 ${ }^{+}$ CD103- (left panel) and IL- $17^{+} \mathrm{CD}^{-} 103^{+}$(right panel) nasal CD4 ${ }^{+} \mathrm{T}_{\mathrm{RM}}$ cells at indicated time points after Bp challenge. $\mathbf{d}$ Absolute numbers of nasal IFN- $\gamma^{+} \mathrm{CD}_{103^{-}}$(left panel) and IFN- $\gamma^{+} \mathrm{CD} 103^{+}$(right panel) $\mathrm{CD} 4^{+} \mathrm{T}_{\mathrm{RM}}$ cells at indicated time points after Bp challenge. Results shown are geometric means \pm SD. $n=6$ per group. Kruskal-Wallis tests were performed to compare aPV $(*)$ and wPV $\left({ }^{*}\right)$ immunized mice to control mice. Only significant differences are indicated. ${ }^{*} P<0.05 ;{ }^{\# \# \#} p<0.001$.

IFN- $\gamma$ deficiency only slightly affected Bp clearance compared to control mice.

We then assessed the effect of aPV and wPV immunization on lung and nasal clearance of $\mathrm{Bp}$ in IL-17 KO mice compared to control mice. With a moderate challenge dose, either vaccine provided protection against lung colonization in IL-17 KO mice similar to the control mice (Supplementary Fig. 3b, c, left panels, respectively), while protection conferred by aPV and wPV was slightly impaired in IL-17 KO mice when mice were infected with a high inoculum (Fig. 4b, left panel and Fig. 4c, left panel, respectively). As expected, neither vaccine was able to provide protection against nasal carriage of the IL-17 KO mice, regardless of the challenge dose (Fig. 4b, c, right panels and Supplementary Fig. 3b, c, right panels).

$\mathrm{T}_{\mathrm{RM}}$ cell-mediated protection against nasal colonization depends on IL-17

As IL-17 appeared to be essential for nasal clearance of $\mathrm{Bp}$ infection, we assessed whether transfer of $\mathrm{IL}-17^{+} \mathrm{CD} 103^{+} \mathrm{CD} 4^{+}$ $T_{R M}$ cells could rescue the ability of IL-17 KO mice to clear nasal infection by $\mathrm{Bp}$. A total of $10^{4} \mathrm{CD} 4^{+} \mathrm{T}_{\mathrm{RM}}$ cells isolated from the noses of C57BL/6 mice 14 d.p.c. were transferred intravenously (i.v.) to IL-17 KO mice (KOt), 10 h.p.c. and 7 d.p.c. (Fig. 5a). Control mice were injected intravenously with phosphate-buffered saline (PBS). CFUs in the noses were counted 3 h.p.c. and 7, 14, and 28 d.p.c. The first transfer of $\mathrm{CD}^{+} \mathrm{T}_{\mathrm{RM}}$ cells did not affect nasal colonization compared to non-transferred mice, as at 7 d.p.c. the bacterial load in the noses of KOt and KO mice were similar (Fig. 5b). After the second transfer given 7 d.p.c., the bacterial load in the noses of KOt mice started to decrease at a rate similar to that of C57BL/ 6 control mice, indicating that the transfer of Bp-induced $\mathrm{CD}^{+}{ }^{+} \mathrm{T}_{\mathrm{RM}}$ cells allowed IL-17 KO mice to reduce nasal Bp infection as efficiently as infected C57BL/6 mice (Fig. 5b).

Lack of $\mathrm{CD}^{+} \mathrm{T}_{\mathrm{RM}}$ cell induction results in lack of neutrophil recruitment

In an attempt to identify the effector cells involved in nasal clearance, we examined the nasal influx of neutrophils upon $\mathrm{Bp}$ infection. $\mathrm{CD}_{4} 5^{+} \mathrm{Ly}-6 \mathrm{G}^{+}$neutrophils infiltrated in the noses of $\mathrm{Bp}$ infected C57BL/6 mice 14 d.p.c. were compared to non-infected mice (Fig. 5c, d). No significant increase in neutrophils was observed in infected IL-17 KO mice, whereas transfer of nasal $\mathrm{CD}^{+}{ }^{+} \mathrm{T}_{\mathrm{RM}}$ cells from Bp-infected $\mathrm{C} 57 \mathrm{BL} / 6$ mice resulted in significant neutrophil recruitment in the noses of IL-17 KO mice 
a
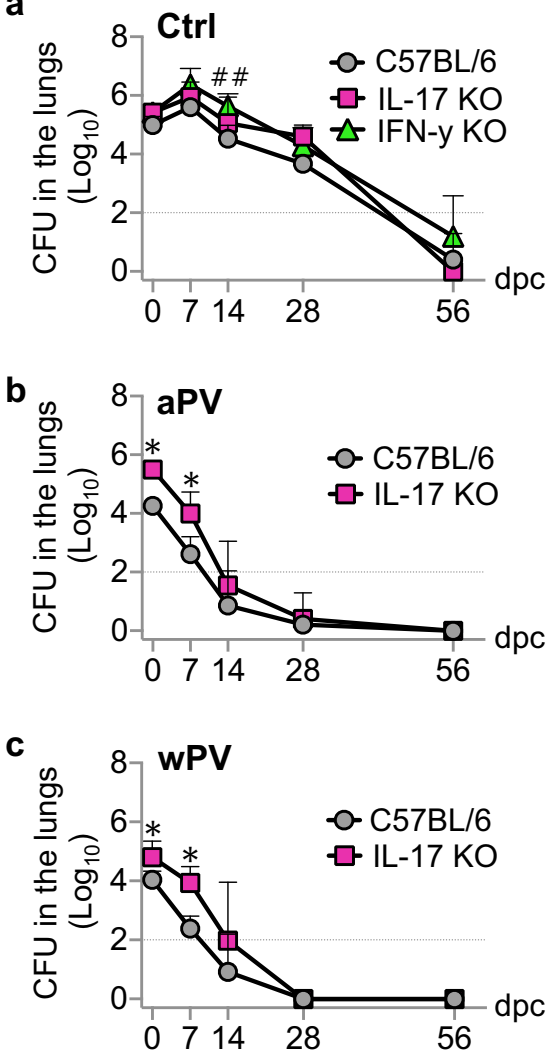
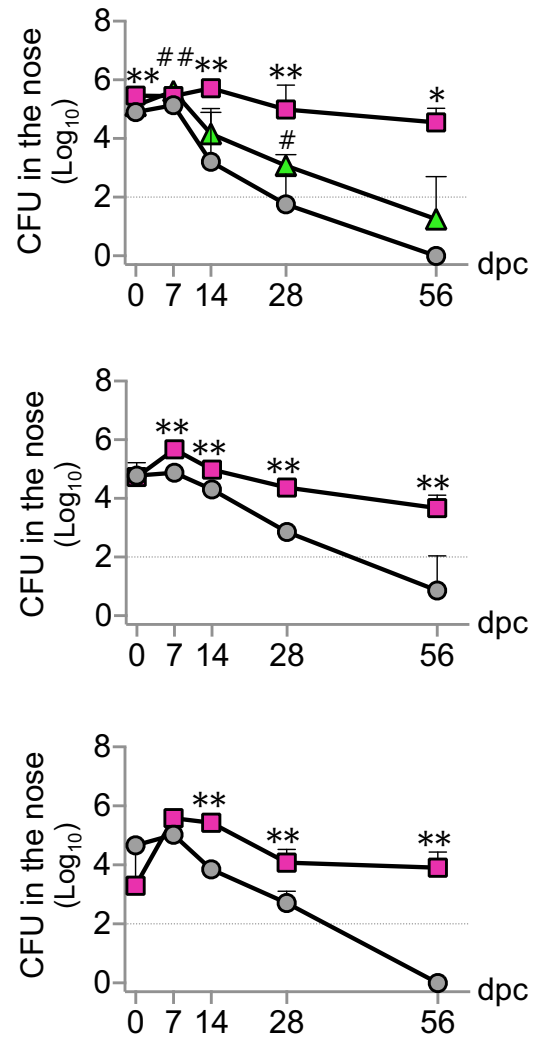

Fig. 4 IL-17 is required for the control of nasal colonization by Bp. a C57BL/6 (in gray), IL-17 KO (in purple), and IFN- $\gamma$ KO (in green) mice were infected with $10^{6} \mathrm{CFU}$ of B1917GR, and CFU numbers were counted in lungs (left panel) and noses (right panel) at indicated time points. b C57BL/6 (in gray), IL-17 KO (in purple) mice were immunized with aPV and then infected with $10^{6}$ CFU of B1917GR, and CFU numbers were counted in lungs (left panel) and noses (right panel) at indicated time points. c C57BL/6 (in gray), IL-17 KO (in purple) mice were immunized with wPV and then infected with $10^{6}$ CFU of B1917GR, and CFU numbers were counted in lungs (left panel) and noses (right panel) at indicated time points. $n=3-5$. Mann-Whitney tests were performed to compare C57BL/6 mice and IL-17 $\left({ }^{*}\right)$ or IFN- $\gamma\left({ }^{\#}\right)$ knockout mice. ${ }^{*} P<$ $0.05,{ }^{* *} p<0.01$, and ${ }^{\# \#} p<0.01$. Only significant differences are indicated. Dashed lines correspond to the detection limit.

14 d.p.c. (Fig. $5 c$, d). The decrease in nasal bacterial loads in C57BL/6 and KOt mice over non-transferred IL-17 KO mice was thus associated with an increase in the amounts of recruited neutrophils (Fig. $5 \mathrm{~d}$ ). Overall, the data suggest that upon $\mathrm{Bp}$ infection nasal $\mathrm{CD}^{+} \mathrm{T}_{\mathrm{RM}}$ cells induce the recruitment of neutrophils by releasing IL-17 and thereby enhance bacterial clearance.

To determine whether the inability of aPV-immunized BALB/C mice to clear the nasal infection by $\mathrm{Bp}$ was also due to their failure in recruiting neutrophils in the noses, we immunized BALB/c mice with aPV or wPV and examined the recruitment of nasal neutrophils over time. While $\mathrm{Bp}$ infection of non-vaccinated $\mathrm{BALB} / \mathrm{C}$ mice resulted in a significant increase in the nasal influx of neutrophils, this influx was totally abolished in aPV-immunized, but not in wPV-immunized mice (Fig. 5e, f). The recruitment of other nasal $\mathrm{CD}^{-} \mathrm{CD}^{-} 1 \mathrm{~b}^{+}$immune cells was not impaired in aPVimmunized mice (Supplementary Fig. 4).

aPV immunization allows extracellular persistence of $\mathrm{Bp}$ in the noses of BALB/c mice

As in vitro data suggest that $\mathrm{Bp}$ can invade and survive within eukaryotic cells ${ }^{25}$ and can also adopt a biofilm lifestyle allowing persistent colonization in mice ${ }^{26}$, we assessed the impact of aPV immunization on intracellular versus extracellular nasal $\mathrm{Bp}$ carriage. aPV- or WPV-immunized BALB/c mice were nasally infected with Bp B1917GR, and nasal washes (NWs) and homogenates were assessed for CFU counts at different time points after challenge (Fig. 6a). The nasal homogenates were treated with collagenase D and DNase I for tissue and biofilm disruption ${ }^{26,27}$. After treatment, the cells were harvested by centrifugation and extracellular bacteria were counted by CFU measurements of the supernatants. To measure the amounts of intracellular bacteria, the cells were washed and incubated with polymyxin B in order to kill potentially remaining extracellular bacteria. Cells were then lysed and intracellular bacteria were quantified by CFU measurements.

Approximately 10- to 100 -fold more bacteria were found in the nasal homogenates compared to the NWs at each time point, suggesting that most bacteria were tightly associated with the nasal epithelium (Fig. 6b). In contrast to control mice and wPVimmunized mice, the bacteria remained associated with the nasal epithelium in aPV-immunized mice for at least up to 56 d.p.c., whereas both vaccines reduced the bacterial load in the NWs (Fig. 6b). Virtually no intracellular bacteria were detected 3 h.p.c. (day 0 ), whereas substantial amounts of intracellular bacteria were detectable at 7 d.p.c., especially in control mice and in aPVimmunized mice (Fig. 6c). Intracellular bacteria were eventually cleared in all three groups 28 d.p.c. (Fig. 6c).

\section{DISCUSSION}

Several reasons have been proposed to explain the resurgence of pertussis, especially in countries using aPV, although many studies have shown a good efficacy of aPV against pertussis disease. These reasons include the rapid waning of protective immunity conferred by $\mathrm{aPV}^{6,28}$ compared to $\mathrm{WPV}^{29,30}$ and the inability of 

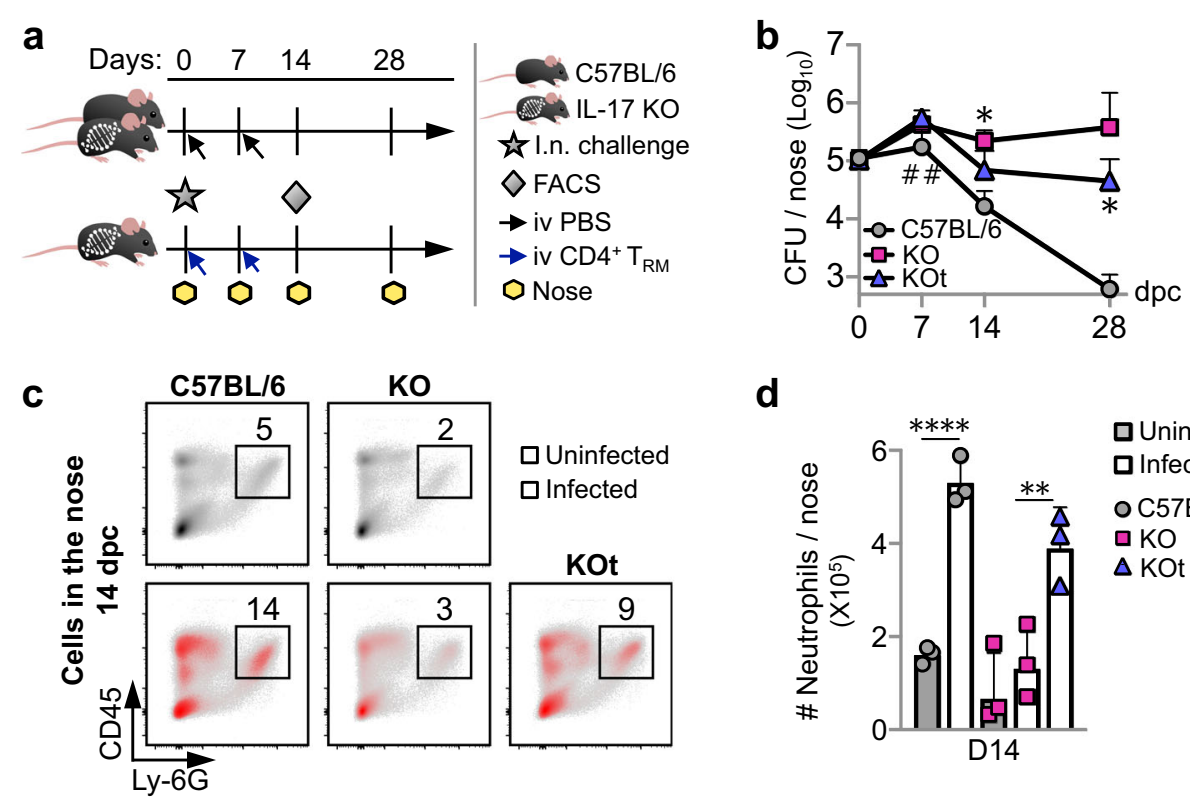

$\square$ Uninfected

d
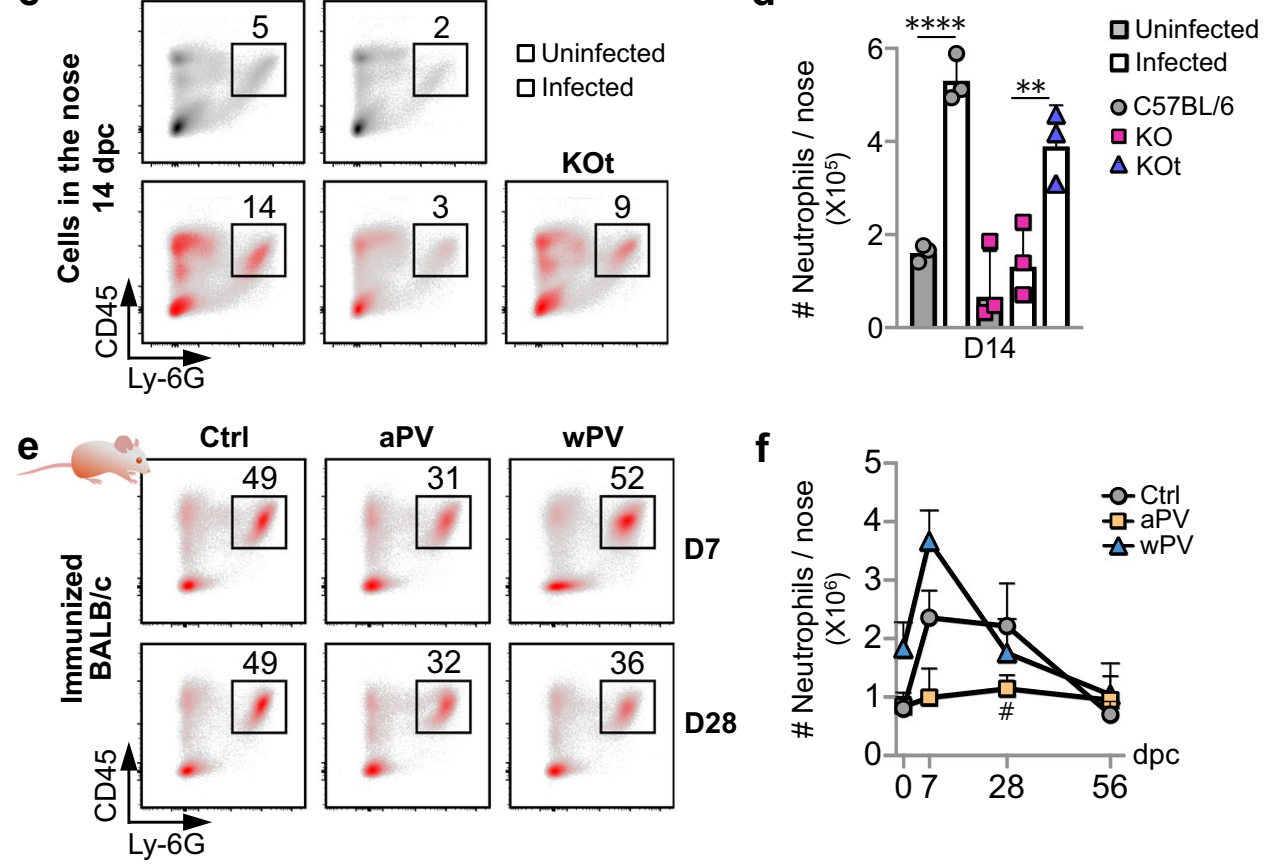

f

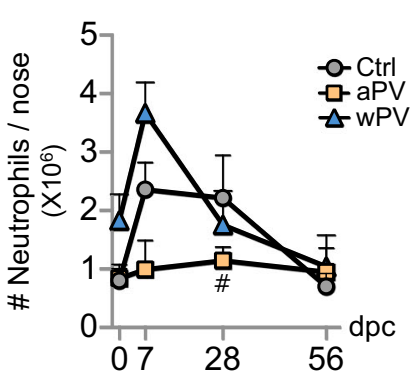

Fig. 5 Bp-specific nasal CD4 ${ }^{+} \mathrm{T}_{\mathrm{RM}}$ cells protect IL-17 KO mice against nasal colonization and induce recruitment of neutrophils. a Schematic of the transfer protocol. C57BL/6 mice were infected nasally (i.n.) with $10^{6} \mathrm{CFU}$ of B1917GR. CD4 ${ }^{+} \mathrm{T}_{\mathrm{RM}}$ cells were purified from noses of infected C57BL/6 mice 14 d.p.c. A total of $10^{4} \mathrm{CD} 4 \mathrm{iv}^{-} \mathrm{CD} 45^{+} \mathrm{CD} 44^{+} \mathrm{CD} 69^{+} \mathrm{CD} 4^{+} \mathrm{T}_{\mathrm{RM}}$ cells were transferred intravenously (i.v.) to IL$17 \mathrm{KO}$ mice 10 h.p.c. and 7 d.p.c. (blue arrows). Control IL-17 KO and C57BL/6 mice received PBS (black arrows). CFU in the nasal tissues was counted at indicated time points post challenge. Nasal cells were collected 14 d.p.c. and analyzed by flow cytometry (FACS). b C57BL/6 (in gray), IL-17 KO (KO, in purple), and transferred IL-17 KO mice (KOt, in blue) were infected with $10^{5}$ CFU of B1917GR, and CFU numbers were counted in the noses at indicated time points. c Representative graphs showing neutrophil (CD45iv ${ }^{-} \mathrm{CD}_{4} 5^{+} \mathrm{Ly}^{-} 6 \mathrm{G}^{+}$) recruitment in the nose of C57BL/6 (left panels), IL-17 KO (KO, middle panels), and transferred IL-17 KO mice (KOt, right panel) mice 14 days after infection with $10^{5}$ CFU of B1917GR. Neutrophil recruitments of non-infected and infected mice are depicted in the upper (gray) and lower (red) panels, respectively. Numbers indicate percentages of events in each square. d C57BL/6 (in gray), IL-17 KO (KO, in purple), and transferred IL-17 KO mice (KOt, in blue) mice were infected with $10^{5} \mathrm{CFU}$ of B1917GR (open bars) or left uninfected (gray bars), and absolute numbers of neutrophils per nose were measured 14 d.p.c. e Representative graphs showing neutrophil $\left(\mathrm{CD} 45^{+} \mathrm{Ly}-6 \mathrm{G}^{+}\right)$recruitment in the nose of BALB/C mice vaccinated with aPV (middle panels) or wPV (right panels) or left unvaccinated (left panels) 7 days ( 7 d.p.c.) and 28 days ( 28 d.p.c.) after infection with $10^{6} \mathrm{CFU}$ of B1917GR. Numbers indicate percentages of events in each square. $f$ Absolute numbers of neutrophils in the noses of $\mathrm{BALB} / \mathrm{c}$ mice immunized with aPV (in yellow) or WPV (in blue), or left un-immunized (in gray) at indicated time points after challenge with $10^{6}$ CFU of B1917GR. Results shown are geometric means \pm SD. $n=3-5$. Ordinary one-way ANOVA (b, d) were performed to compare KO mice to $\mathrm{KOt}\left({ }^{*}, \mathbf{b}, \mathbf{d}\right)$ or to $\mathrm{C} 57 \mathrm{BL} / 6$ mice $(\#, \mathbf{b})$ and to evaluate the induction of neutrophils in infected C57BL/6 $\left({ }^{*}, \mathbf{d}\right)$. Kruskal-Wallis tests were performed to compare aPV $\left({ }^{\#}\right)$ and WPV $\left({ }^{*}\right)$ immunized BALB/c mice to control mice (f). ${ }^{* * *} p<0.05,{ }^{* * * \# *} p<0.001$, ${ }^{* * *} p<0.001$, and ${ }^{* * * *} p<$ 0.0001. Only significant differences are indicated.

aPV, as well as of wPV to prevent Bp infection and pertussis transmission. Using mouse models, we show here that in addition to the failure of immunization with aPV or wPV to protect against nasal colonization aPV immunization resulted in substantially prolonged nasal Bp carriage in Th2-prone BALB/C mice when compared to non-immunized mice, while it was protective against lung colonization. These findings are consistent with observations in a non-human primate model showing that aPV immunization, while protecting against disease, caused prolonged carriage of $\mathrm{Bp}$ challenged baboons ${ }^{8}$. We found that aPV-induced prolonged nasal carriage in BALB/c mice was paralleled with vaccinemediated inhibition of nasal IL-17- and/or IFN- $\gamma$-producing
$\mathrm{CD} 103^{+} \mathrm{CD}^{+} \mathrm{T}_{\mathrm{RM}}$ cells induced by Bp infection. Recently, Wilk et al. $^{20}$ showed that, in contrast to WPV immunization, aPV immunization fails to expand $T_{R M}$ cells in the lungs and noses and provided evidence that $T_{R M}$ cells promote bacterial clearance in mouse lungs by adoptive transfer of $\mathrm{CD}^{+} \mathrm{T}_{\mathrm{RM}}$ cells in irradiated mice or by treating mice with FTY720 during the immunization phase, which prevents migration of $T$ and $B$ cells from lymph nodes to the circulation ${ }^{19,20}$. We found here that aPV not only fails to induce $\mathrm{IL}-17^{+}$and/or IFN- $\gamma^{+} \mathrm{CD}^{+}{ }^{+} \mathrm{T}_{\mathrm{RM}}$ cells, but even prevents the induction of these cells in the nasal tissue of Bp-infected BALB/ $c$ mice, while they were strongly induced in non-vaccinated mice upon Bp challenge, peaking at 14 d.p.c., and were maintained for 

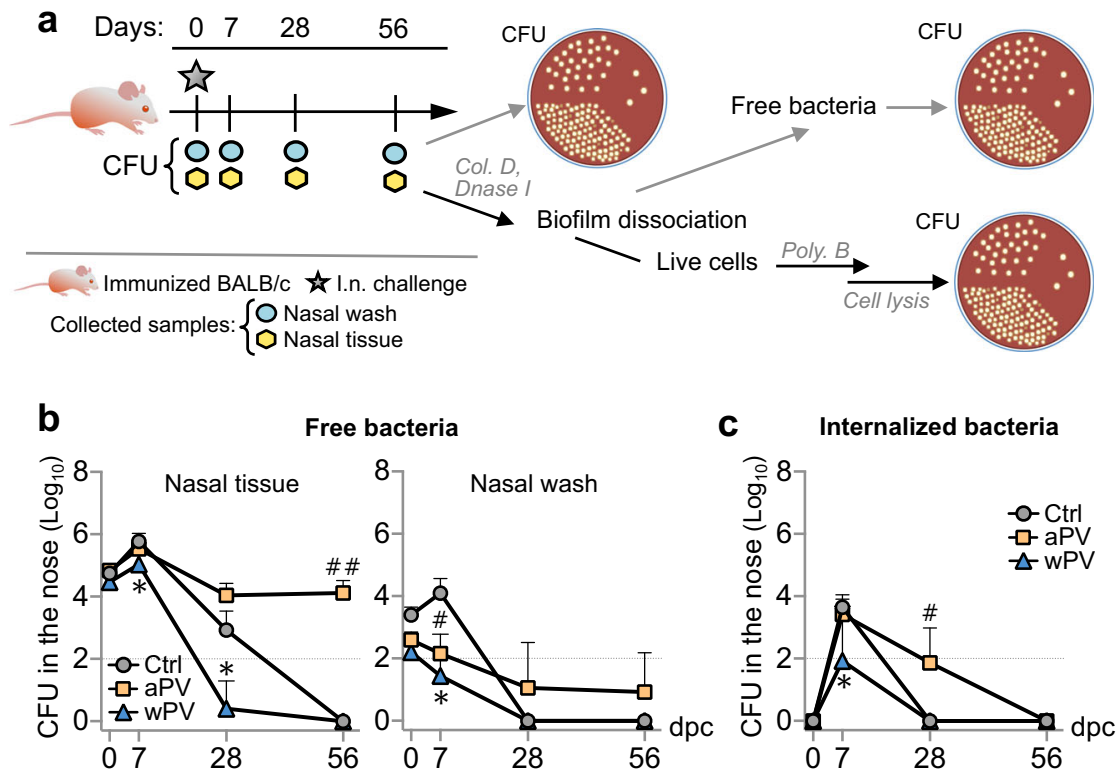

Fig. 6 aPV immunization prevents clearance of extracellular, tightly adhering $B p$ in the noses of BALB/c mice. a Schematic of experimental procedures. aPV- (in yellow in b, c), wPV-immunized (in blue in b, c) or control BALB/c mice (Ctrl, in gray in b, c) were challenged with $10^{6} \mathrm{CFU}$ of B1917GR and euthanized at indicated time points post challenge. NWs were collected before nose harvest to count extracellular CFU in the nasal fluids. Nasal tissue was digested with collagenase D (col. D) and DNase I for biofilm dissociation, flushed, and passed through a cell strainer to obtain a single-cell suspension. Cells were pelleted and extracellular CFUs were counted. Cells were incubated with polymyxin B (poly. B), washed and lysed to estimate the number of intracellular CFU. b Extracellular CFU in the nasal tissues (left panel) and nasal washes (right panel). c Intracellular CFU in the nasal tissue. Results shown are geometric means \pm SD. $n=3-5$. Kruskal-Wallis tests were performed to compare aPV- and wPV-immunized mice to control mice. ${ }^{*, \#} P<0.05 ;{ }^{* *, \# \#} p<0.01$. Only significant differences are indicated. Dashed lines in $\mathbf{b}$, $\mathbf{c}$ correspond to the detection limit.

at least up to 28 d.p.c. In contrast, in wPV-immunized mice, these cells were induced earlier than in non-vaccinated mice, and peaked at 7 d.p.c., which was paralleled by a significant decrease in bacterial burden in the noses of wPV-immunized BALB/c mice 7 d.p.c. compared to non-vaccinated controls.

While $\mathrm{Bp}$ infection resulted in the expansion of both IFN- $\gamma$ producing Th1 and IL-17-producing Th17 CD4 ${ }^{+} \mathrm{T}_{\mathrm{RM}}$ cells in the nasal tissue, the latter were the main cells involved in the control of nasal colonization by $\mathrm{Bp}$, as IL-17 KO mice were unable to clear nasal $\mathrm{Bp}$ infection, while able to control lung infection as well as control mice. In contrast, IFN- $\gamma$ KO mice cleared the infection both in lungs and noses, similar to control mice. Furthermore, adoptive cell transfer of nasal $\mathrm{CD}^{+}{ }^{+} \mathrm{T}_{\mathrm{RM}}$ cells isolated from Bp-infected C57BL/6 mice to IL-17-deficient mice conferred protection against nasal colonization. Thus, aPV immunization prevents nasal Bp clearance in Th2-prone mice by preventing the natural induction of nasal IL-17 ${ }^{+} \mathrm{CD}_{103^{+}} \mathrm{CD}^{+}{ }^{+} \mathrm{T}_{\mathrm{RM}}$ cells upon Bp infection.

IL-17 deficiency was associated with failure to recruit neutrophils upon Bp infection, and adoptive transfer of Th17 $\mathrm{T}_{\mathrm{RM}}$ cells to IL-17 KO mice was associated with accelerated neutrophil recruitment, suggesting that Th17 $\mathrm{T}_{\mathrm{RM}}$ cells control the outcome of the infection by enhancing neutrophil recruitment in the noses of Bp-infected mice. Through releasing of IL-17, Th17 T cells are known to attract neutrophils to the site of infection via CXC chemokines and to modulate neutrophil granulopoiesis via the induction of endogenous granulocyte colony-stimulating factor and stem cell factor ${ }^{31,32}$. Consistent with a protective role of neutrophils in immunized or convalescent mice, neutropenia severely impairs clearance ${ }^{33}$. Furthermore, Bp clearance from mouse lungs after the transfer of antibodies from convalescent mice was abrogated by neutrophil depletion or Fcy receptor deletion ${ }^{34}$, suggesting that neutrophils mediate the killing of Bp in the lungs by opsonic phagocytosis. We recently showed that passive transfer of serum from aPV-immunized mice or mice immunized with the live attenuated BPZE1 vaccine conferred protection in the lungs of severe combined immunodeficiency mice but not in the nose, suggesting that serum immunoglobulins (Igs) do not efficiently protect in the nose ${ }^{21}$. Instead, by using knockout models and passive transfer of mucosal lgs, it was demonstrated that mucosal IgA induced by BPZE1 contributes to nasal protection as well as IL-17, possibly through the induction of Th17 $\mathrm{T}_{\text {RM }}$ cells.

We found that $\mathrm{Bp}$ was present in three locations in the noses of $\mathrm{BALB} / \mathrm{C}$ mice. A minority was loosely attached to the nasal epithelium and could easily be recovered in NWs. A small fraction was found in intracellular compartments and the vast majority of Bp organisms was tightly attached to the nasal epithelium. Both WPV and aPV immunization diminished the loosely attached bacteria, suggesting that they may have been cleared by transuded wPV- or aPV-induced serum antibodies. Immunization with aPV slightly prolonged the presence of intracellular bacteria in the noses of BALB/c mice. The strongest effect of aPV immunization was seen on the Bp organisms that were tightly attached to the nasal epithelium, suggesting a major role of $\mathrm{IL}-17^{+} \mathrm{T}_{\mathrm{RM}}$ cells in clearing tightly attached bacteria. IL-17 plays a central role in maintaining the mucosal barrier integrity ${ }^{35,36}$, and Bp has been shown to alter the epithelial cell barrier ${ }^{37}$, which results in the exposure of cryptic receptors on the basement membrane allowing the pathogen to attach more efficiently ${ }^{38}$.

The localization of $\mathrm{CD}_{103^{+}} \mathrm{CD}^{+} \mathrm{T}_{\mathrm{RM}}$ cells in the nasal epithelium positions them well to act as the first line of defense at subsequent exposure to Bp. While $\mathrm{CD}_{103^{+}} \mathrm{T}_{\mathrm{RM}}$ cells interact with epithelial cells through E-cadherin ${ }^{39,40}, \mathrm{CD}_{4} 4^{+}$T cells may be retained in the underlying extracellular matrix ${ }^{41}$. The greatest differences in $T_{R M}$ cell numbers and activation between aPVimmunized BALB/C mice and control mice were observed in the $\mathrm{CD} 103^{+}$subset of $\mathrm{T}_{\mathrm{RM}}$ cells. In addition, early accumulation of $\mathrm{CD}_{103^{+}} \mathrm{T}_{\mathrm{RM}}$ cells by wP-primed mice compared to control mice was associated with a decrease in nasal bacterial burden at early 
time points after Bp infection, thereby confirming the importance of these cells to clear bacteria in the nose. Augmented expression of IL-17/IFN- $\gamma$ double-positive cells in the $\mathrm{CD} 103^{+} \mathrm{T}_{\mathrm{RM}}$ cell subset may enhance local immune responses in the nasal mucosa, as these cytokines are known to enhance phagocytosis. In addition, IL-17/IFN- $\gamma$ double-positive cells have been shown to induce the expression of antimicrobial genes by epithelial cells, further suggesting a protective role of $\mathrm{CD}_{103^{+}} \mathrm{T}_{\mathrm{RM}}$ cells $^{42}$.

In conclusion, we provide evidence here that aPV immunization may prolong nasal carriage of $\mathrm{Bp}$ and thereby increase the $\mathrm{Bp}$ reservoir in aPV-immunized populations, which may have contributed to the increase in pertussis incidence in countries in which aPV are in use. The effect of aPV on the prolonged nasal carriage was seen in Th2-prone BALB/c mice, which were unable to clear nasal $\mathrm{Bp}$ carriage, especially $\mathrm{Bp}$ organisms that tightly adhere to the nasal epithelium, for at least up to 56 d.p.c. These findings are relevant in the context of newborns in which a bias toward a Th2-type differentiation has been demonstrated ${ }^{22}$, but may also be relevant for older Th2-prone individuals. The aPV effect on nasal carriage is due to aPV-mediated inhibition of IL-17 ${ }^{+}$ $\mathrm{CD}_{103}{ }^{+} \mathrm{CD}^{+} \mathrm{T}_{\mathrm{RM}}$ cells expansion, which in turn prevents neutrophil recruitment important for bacterial clearance. This study provides thus a coherent explanation of how aPV enhances nasal carriage of $\mathrm{Bp}$ and supports the hypothesis of asymptomatic $\mathrm{Bp}$ carriage and transmission as a major driver of pertussis resurgence in countries that have switched from wPV to aPV immunization programs ${ }^{9}$. However, aPV induces antibodies that provide protection against lung colonization in mice and against pertussis disease in humans, which is the purpose of these vaccines.

\section{METHODS}

\section{Bacterial strain}

Bp strain B1917, a pertactin-producing strain, came from the RIVM collection (Bilthoven, The Netherlands). For counter selection purposes, B1917 was electroporated with the pFUS2-BctA1 suicide plasmid to acquire gentamicin resistance as described ${ }^{43}$, thereby yielding B1917GR. After electroporation, gentamicin-resistant derivatives were checked by $P C R$ to verify the site of insertion of the pFUS2-BctA1 suicide vector in the bacterial genome. Bacteria were cultured at $37^{\circ} \mathrm{C}$ on Bordet-Gengou (BG) agar (Difco Bordet-Gengou Agar Base), supplemented with 1\% glycerol, $10 \%$ defibrinated sheep blood, and $10 \mu \mathrm{g} / \mathrm{ml}$ gentamycin, as described ${ }^{44}$. After $40 \mathrm{~h}$ of growth, the bacteria were harvested by scraping the plates and resuspended in PBS at the density of $5 \times 10^{7}$ or $5 \times 10^{6} \mathrm{CFU} / \mathrm{ml}$. Whole $B$. pertussis cell lysates were prepared and used for antibody determination as described ${ }^{45}$.

\section{Animals and ethical statement}

$\mathrm{BALB} / \mathrm{C}$ and $\mathrm{C} 57 \mathrm{BL} / 6$ mice were purchased from Charles Rivers France. IL17 and IFN- $\gamma$ KO mice were kindly provided by F. Trottein (Institut Pasteur de Lille). All the animal experiments were carried out in accordance with the guidelines of the French Ministry of Research, and the protocols were approved by the Ethical Committees of the Region Nord Pas de Calais and the Ministry of Research (agreement number APAFIS \# 2019052015506229 V3).

\section{Protection experiments}

Mice were immunized subcutaneously with $1 / 10$ human dose of aPV (Infanrix, GlaxoSmithKline) or wPV (Shan5, Shantha Biotechnics, India) and boosted 4 weeks later with the same dose. Control mice were injected with PBS. Eight weeks after the first immunization, mice were challenged intranasally with $10^{6}$ or $10^{5}$ CFU of virulent B1917GR. Mice were euthanized at different times post challenge, that is 3 h.p.c. and 7, 14, 28, and 56 d.p.c. NWs were performed with stainless steel feeding tubes $(24 \mathrm{ga} \times 25 \mathrm{~mm}$, Phymep). One milliliter of PBS was slowly injected through the trachea and the NW was collected. Lungs and noses were harvested and homogenized for CFU measurement by plating 10-fold serial dilutions onto BG agar plates containing $10 \mu \mathrm{g} / \mathrm{ml}$ gentamicin as described ${ }^{21}$.

\section{Cell isolation for CFU tests}

Infected $B A L B / C$ mice were euthanized at different times post challenge ( 3 h.p.c. and 7, 28, and 56 d.p.c.). NWs were collected prior to nose harvest to assess extracellular CFU in the nasal fluid. Nasal tissue was scraped from the nasal cavity, cut into small pieces, and digested with collagenase D $(0.6 \mathrm{mg} / \mathrm{ml}$; Roche) and DNase I (20 U/ml; Sigma-Aldrich) for $40 \mathrm{~min}$ at $37^{\circ} \mathrm{C}$. The nasal tissue was flushed several times and then passed through a cell strainer to obtain a single-cell suspension. Cells were pelleted and the supernatant was conserved to assess extracellular CFU. Cells were washed twice and then incubated for $1 \mathrm{~h}$ with $100 \mu \mathrm{g} / \mathrm{ml}$ polymyxin B sulfate (Sigma) to eliminate extracellular bacteria ${ }^{46}$. Cells were washed twice and then lysed with $0.1 \%$ saponin (Sigma). CFU counting was performed on cell lysates by plating 10-fold serial dilutions onto BG agar plates containing $10 \mu \mathrm{g} / \mathrm{ml}$ gentamicin to estimate the number of intracellular bacteria.

\section{Cell isolation for flow cytometry analysis}

Ten minutes before euthanasia, mice were injected intravenously with $10 \mu \mathrm{g}$ of anti-CD45-PE antibody from eBioscience (30-F11, catalog\#120451-82) to allow for the distinction of circulating $T$ cells $\left(C D 45-\mathrm{PE}^{+}\right)$and resident $T$ cells or infiltrated immune cells $\left(C D 45-P^{-}\right)$. Nasal tissue was treated as described above. Red blood cells were lysed using ACK lysing buffer (Gibco). Isolated cells were stimulated with $50 \mathrm{ng} / \mathrm{ml}$ phorbol myristate (InVivoGen) and $500 \mathrm{ng} / \mathrm{ml}$ ionomycin (Sigma) in the presence of $5 \mu \mathrm{g} / \mathrm{ml}$ brefeldin A (Sigma) for $4 \mathrm{~h}$ at $37^{\circ} \mathrm{C}$. Cells were incubated with Dead Cell Stain Kit LIVE/DEAD Aqua (Invitrogen) first as recommended by the supplier, then with Fc block (BD Biosciences, dilution 1:50), followed by surface staining with the following fluorochrome-conjugated antibodies (dilution 1:400): CD45-APC (30-F11, catalog\#559864), CD69-FITC (H1.2F3, catalog\#11-0691-82), CD8-AF700 (53-6.7, catalog\#56-0081-82), CD3-APCeF780 (17A2, catalog\#47-0032-82) from eBioscience, CD44-BV605 (IM7, catalog\#103047), CD4-BV785 (RM4-5, catalog\#100552) from BioLegend, and CD103-PE-CF594 (M290, catalog\#565849) from BD Biosciences. For the detection of intracellular cytokines, cells were fixed and permeabilized using a FoxP3 transcription factor staining buffer set (eBioscience), incubated with normal rat serum (eBioscience) (1:50), and stained with the following antibodies: IL-17-V450 (TC11-18H10, catalog\#560522, dilution 1:200) from BD Biosciences and IFN- - -PE-Cy7 (XMG1.2, catalog\#257319-41, dilution 1:400) from eBioscience. Fluorescence minus one sample were used as controls. The gating strategy for the identification of $\mathrm{IL}-17^{+}$ $T_{R M}$ cells is shown in Supplementary Fig. 5a. Fluorescence-activated cell sorting samples were acquired on an LSR Fortessa using the BD Diva Software (BD Biosciences) and analyzed using the FlowJo Software ( $\mathrm{v} 10$, TreeStar). Neutrophils were identified with Ly-6G-PE-CF594 (1A8, catalog\#562700, dilution 1:400) and CD11b-BV605 (M1/70, catalog\#563015, dilution 1:400) antibodies from BD Biosciences (see Supplementary Fig. $5 b$ ). The total number of cells was calculated by multiplying the number of registered events by the ratio of $\mathrm{CD} 45-\mathrm{APC}^{+}$cells over the absolute number of immune cells in the nasal tissue, determined by counting live immune cells in a hemocytometer.

\section{Adoptive transfer of $\mathrm{CD} 4{ }^{+} \mathrm{T}_{\mathrm{RM}}$ cells from the nose}

$\mathrm{CD}^{+} \mathrm{T}_{\mathrm{RM}}$ cells were purified from noses of $\mathrm{C} 57 \mathrm{BL} / 6$ mice infected with $10^{6} \mathrm{CFU}$ of B1917GR 14 d.p.c. Cells were treated as described above. $\mathrm{CD}_{4} \mathrm{iv}^{-} \mathrm{CD}_{4} 5^{+} \mathrm{CD}_{4} 4^{+} \mathrm{CD} 69^{+} \mathrm{CD}^{+}{ }^{+}$cells were sorted using BD FACS Aria Il sorter (BD Biosciences). Purity of the isolated cells was checked prior to transfer (Supplementary Fig. 6). A total of $10^{4}$ cells were transferred intravenously to IL-17 KO mice 10 h.p.c. and 7 d.p.c.

\section{Statistical analyses}

Statistical analyses were performed by non-parametric $T$ tests, Kruskal-Wallis, or one-way analysis of variance tests and Mann-Whitney tests using the GraphPad Prism software. $P$ values $<0.05$ were considered significant.

\section{Reporting summary}

Further information on research design is available in the Nature Research Reporting Summary linked to this article. 


\section{DATA AVAILABILITY}

The authors confirm that the data supporting the findings of this study are available within the article and its Supplementary Materials. All other relevant data are available from the corresponding author on reasonable request.

Received: 3 August 2020; Accepted: 8 December 2020;

Published online: 08 January 2021

\section{REFERENCES}

1. Hewlett, E. L. \& Edwards, K. M. Clinical practice. Pertussis-not just for kids. N. Engl. J. Med. 352, 1215-1222 (2005).

2. Locht, C. Will we have new pertussis vaccines? Vaccine 36, 5460-5469 (2018).

3. Cherry, J. D. Epidemic pertussis in 2012-the resurgence of a vaccine-preventable disease. N. Engl. J. Med. 367, 785-787 (2012).

4. Peck, M. Global routine vaccination coverage, 2018. Morb. Mortal. Wkly. Rep. 68 , 937-942 (2019)

5. Gustafsson, L., Hessel, L., Storsaeter, J. \& Olin, P. Long-term follow-up of Swedish children vaccinated with acellular pertussis vaccines at 3,5, and 12 months of age indicates the need for a booster dose at 5 to 7 years of age. Pediatrics 118, 978-984 (2006).

6. Klein, N. P., Bartlett, J., Rowhani-Rahbar, A., Fireman, B. \& Baxter, R. Waning protection after fifth dose of acellular pertussis vaccine in children. N. Engl. J. Med. 367, 1012-1019 (2012)

7. Gambhir, M. et al. A change in vaccine efficacy and duration of protection explains recent rises in pertussis incidence in the United States. PLoS Comput. Biol. 11, e1004138 (2015).

8. Warfel, J. M., Zimmerman, L. I. \& Merkel, T. J. Acellular pertussis vaccines protect against disease but fail to prevent infection and transmission in a nonhuman primate model. Proc. Natl Acad. Sci. USA 111, 787-792 (2014).

9. Althouse, B. M. \& Scarpino, S. V. Asymptomatic transmission and the resurgence of Bordetella pertussis. BMC Med. 13, 146 (2015).

10. Morse, S. I. \& Barron, B. A. Studies on the leukocytosis and lymphocytosis induced by Bordetella pertussis. 3. The distribution of transfused lymphocytes in pertussistreated and normal mice. J. Exp. Med. 132, 663-672 (1970).

11. Pittman, M., Furman, B. L. \& Wardlaw, A. C. Bordetella pertussis respiratory tract infection in the mouse: pathophysiological responses. J. Infect. Dis. 142, 56-66 (1980).

12. Higgs, R., Higgins, S. C., Ross, P. J. \& Mills, K. H. G. Immunity to the respiratory pathogen Bordetella pertussis. Mucosal Immunol. 5, 485-500 (2012).

13. Redhead, K., Watkins, J., Barnard, A. \& Mills, K. H. Effective immunization against Bordetella pertussis respiratory infection in mice is dependent on induction of cell-mediated immunity. Infect. Immun. 61, 3190-3198 (1993).

14. Mills, K. H., Ryan, M., Ryan, E. \& Mahon, B. P. A murine model in which protection correlates with pertussis vaccine efficacy in children reveals complementary roles for humoral and cell-mediated immunity in protection against Bordetella pertussis. Infect. Immun. 66, 594-602 (1998)

15. Mills, K. H., Barnard, A., Watkins, J. \& Redhead, K. Cell-mediated immunity to Bordetella pertussis: role of Th1 cells in bacterial clearance in a murine respiratory infection model. Infect. Immun. 61, 399-410 (1993).

16. Mahon, B. P., Brady, M. T. \& Mills, K. H. Protection against Bordetella pertussis in mice in the absence of detectable circulating antibody: implications for longterm immunity in children. J. Infect. Dis. 181, 2087-2091 (2000).

17. Barbic, J., Leef, M. F., Burns, D. L. \& Shahin, R. D. Role of gamma interferon in natural clearance of Bordetella pertussis infection. Infect. Immun. 65, 4904-4908 (1997).

18. da Silva Antunes, R. et al. Th1/Th17 polarization persists following whole-cell pertussis vaccination despite repeated acellular boosters. J. Clin. Invest. 128, 3853-3865 (2018).

19. Wilk, M. M. et al. Lung CD4 tissue-resident memory $T$ cells mediate adaptive immunity induced by previous infection of mice with Bordetella pertussis. $J$ Immunol. 199, 233-243 (2017).

20. Wilk, M. M. et al. Immunization with whole cell but not acellular pertussis vaccines primes CD4 TRM cells that sustain protective immunity against nasal colonization with Bordetella pertussis. Emerg. Microbes Infect. 8, 169-185 (2019).

21. Solans, L. et al. IL-17-dependent SlgA-mediated protection against nasal Bordetella pertussis infection by live attenuated BPZE1 vaccine. Mucosal Immunol. 11, 1753-1762 (2018).

22. Zaghouani, H., Hoeman, C. M. \& Adkins, B. Neonatal immunity: faulty T-helpers and the shortcomings of dendritic cells. Trends Immunol. 30, 585-591 (2009).

23. Bart, M. J. et al. Complete genome sequences of Bordetella pertussis isolates B1917 and B1920, representing two predominant global lineages. Genome Announc. 2, e01301-e01314 (2014).
24. Allen, A. C. \& Mills, K. H. G. Improved pertussis vaccines based on adjuvants that induce cell-mediated immunity. Expert Rev. Vaccines 13, 1253-1264 (2014).

25. Ewanowich, C. A., Melton, A. R., Weiss, A. A., Sherburne, R. K. \& Peppler, M. S Invasion of HeLa 229 cells by virulent Bordetella pertussis. Infect. Immun. 57, 2698-2704 (1989).

26. Cattelan, N., Dubey, P., Arnal, L., Yantorno, O. M. \& Deora, R. Bordetella biofilms: a lifestyle leading to persistent infections. Pathog. Dis 74, ftv108 (2016).

27. Conover, M. S., Sloan, G. P., Love, C. F., Sukumar, N. \& Deora, R. The Bps polysaccharide of Bordetella pertussis promotes colonization and biofilm formation in the nose by functioning as an adhesin. Mol. Microbiol. 77, 1439-1455 (2010).

28. Ausiello, C. M., Urbani, F., la Sala, A., Lande, R. \& Cassone, A. Vaccine- and antigendependent type 1 and type 2 cytokine induction after primary vaccination of infants with whole-cell or acellular pertussis vaccines. Infect. Immun. 65 2168-2174 (1997).

29. Witt, M. A., Katz, P. H. \& Witt, D. J. Unexpectedly limited durability of immunity following acellular pertussis vaccination in preadolescents in a North American outbreak. Clin. Infect. Dis. Publ. Infect. Dis. Soc. Am. 54, 1730-1735 (2012).

30. van der Lee, S., Hendrikx, L. H., Sanders, E. A. M., Berbers, G. A. M. \& Buisman, A.-M Whole-cell or acellular pertussis primary immunizations in infancy determines adolescent cellular immune profiles. Front. Immunol. 9, 51 (2018).

31. Schwarzenberger, P. et al. IL-17 stimulates granulopoiesis in mice: use of an alternate, novel gene therapy-derived method for in vivo evaluation of cytokines. J. Immunol. 161, 6383-6389 (1998).

32. Schwarzenberger, P. et al. Requirement of endogenous stem cell factor and granulocyte-colony-stimulating factor for IL-17-mediated granulopoiesis. J. Immunol. 164, 4783-4789 (2000).

33. Andreasen, C. \& Carbonetti, N. H. Role of neutrophils in response to Bordetella pertussis infection in mice. Infect. Immun. 77, 1182-1188 (2009).

34. Kirimanjeswara, G. S., Agosto, L. M., Kennett, M. J., Bjornstad, O. N. \& Harvill, E. T. Pertussis toxin inhibits neutrophil recruitment to delay antibody-mediated clearance of Bordetella pertussis. J. Clin. Invest. 115, 3594-3601 (2005).

35. Maxwell, J. R. et al. Differential roles for interleukin-23 and interleukin-17 in intestinal immunoregulation. Immunity 43, 739-750 (2015).

36. Lee, J. S. et al. Interleukin-23-independent IL-17 production regulates intestinal epithelial permeability. Immunity 43, 727-738 (2015).

37. de Gouw, D., Diavatopoulos, D. A., Bootsma, H. J., Hermans, P. W. M. \& Mooi, F. R. Pertussis: a matter of immune modulation. FEMS Microbiol. Rev. 35, 441-474 (2011).

38. Eby, J. C. et al. Selective translocation of the Bordetella pertussis adenylate cyclase toxin across the basolateral membranes of polarized epithelial cells. J. Biol. Chem. 285, 10662-10670 (2010).

39. Gebhardt, T. et al. Memory T cells in nonlymphoid tissue that provide enhanced local immunity during infection with herpes simplex virus. Nat. Immunol. 10, 524-530 (2009).

40. Thome, J. J. C. \& Farber, D. L. Emerging concepts in tissue-resident T cells: lessons from humans. Trends Immunol. 36, 428-435 (2015).

41. Masopust, D. et al. Dynamic T cell migration program provides resident memory within intestinal epithelium. J. Exp. Med. 207, 553-564 (2010).

42. Boniface, K. et al. Human Th17 cells comprise heterogeneous subsets including IFN-gamma-producing cells with distinct properties from the Th1 lineage. J. Immunol. 185, 679-687 (2010).

43. Antoine, R. et al. The periplasmic binding protein of a tripartite tricarboxylate transporter is involved in signal transduction. J. Mol. Biol. 351, 799-809 (2005).

44. Mielcarek, N. et al. Live attenuated $B$. pertussis as a single-dose nasal vaccine against whooping cough. PLoS Pathog. 2, e65 (2006).

45. Debrie, A. S. et al. Early protection against pertussis induced by live attenuated Bordetella pertussis BPZE1 depends on TLR4. J. Immunol. 203, 3293-3300 (2019).

46. Lamberti, Y. A., Hayes, J. A., Perez Vidakovics, M. L., Harvill, E. T. \& Rodriguez, M. E. Intracellular trafficking of Bordetella pertussis in human macrophages. Infect. Immun. 78, 907-913 (2010).

\section{ACKNOWLEDGEMENTS}

We thank François Trottein for the gift of IL-17 and of IFN- $\gamma$ KO mice, and Ludovic Mercier for the maintenance of the mouse strains. We also thank the Bioimaging Center platform (BICeL) for the flow cytometry. Part of this work has been financially supported by The PERISCOPE (PERtussIS COrrelates of Protection Europe) consortium. V.D. and J.C. are supported by PERISCOPE (grant \#115910). This PERISCOPE project has received funding from the Innovative Medicines Initiative 2 Joint. This Joint Undertaking receives support from the European Union's Horizon 2020 research and innovation program and EFPIA and BMGF. 


\section{AUTHOR CONTRIBUTIONS}

V.D. and C.L. designed the experiments; V.D., J.C., H.B.-L.R., A.T., and A.-S.D. performed the experiments; modified gentamicin-resistant Bp was constructed by L.C. V.D., A.T., and J.C. analyzed the data; V.D. and C.L. wrote the manuscript.

\section{COMPETING INTERESTS}

The authors declare no competing interests.

\section{ADDITIONAL INFORMATION}

Supplementary information is available for this paper at https://doi.org/10.1038/ s41541-020-00270-8.

Correspondence and requests for materials should be addressed to V.D.

Reprints and permission information is available at http://www.nature.com/ reprints
Publisher's note Springer Nature remains neutral with regard to jurisdictional claims in published maps and institutional affiliations.

(i) Open Access This article is licensed under a Creative Commons Attribution 4.0 International License, which permits use, sharing, appropriate credit to the original author(s) and the source, provide a link to the Creative Commons license, and indicate if changes were made. The images or other third party material in this article are included in the article's Creative Commons license, unless indicated otherwise in a credit line to the material. If material is not included in the article's Creative Commons license and your intended use is not permitted by statutory regulation or exceeds the permitted use, you will need to obtain permission directly from the copyright holder. To view a copy of this license, visit http://creativecommons. org/licenses/by/4.0/.

(c) The Author(s) 2021 